\title{
Development of Networks Model in The Serious Game of Agribusiness Management for Decision Making \\ ${ }^{1}$ Saiful Bukhori, ${ }^{2}$ Wiji Utami, ${ }^{3}$ Anang Andrianto \\ 1,3 Information System Department, \\ ${ }^{2}$ Economics Faculty, \\ Jember University, Indonesia \\ email: saiful.ilkom@unej.ac.id
}

\begin{abstract}
This research developed a decision-making process in the agribusiness management system and analyzed the behavior of fixed point for identifying the position of agribusiness interaction. Agribusiness is represented as node that work together in the market to maintain the stability of market. Based on agribusiness management and data modeling, there are four conditions of the inter-company networks: (1) mutual dependence, (2) mutual independence, (3) unbalanced dependece, (4) unbalanced independence. The experiment results are the mutual dependence conditioan the fixed point towards stable value come near 0 . The mutual independence, fixed point towards stable value, but stability value still not yet come near 0 . The unbalanced dependece, fixed point oscillate and convergence. While the unbalanced independence, fixed point start oscillation.
\end{abstract}

\section{Indexing terms/Keywords}

agribusiness management, serious game, fixed point, dependence, independence.

\section{Academic Discipline And Sub-Disciplines}

Computer Science, Game Technology

\section{SUBJECT CLASSIFICATION}

Artificial Intelligence, Serious Game

\section{Council for Innovative Research}

Peer Review Research Publishing System

\section{Journal: INTERNATIONAL JOURNAL OF COMPUTERS \& TECHNOLOGY}

\author{
Vol 10, No 8 \\ editor@cirworld.com
}




\section{INTRODUCTION}

Definitions of agribusiness has been discussed by several experts, according to Downey and Erickson [9], "Agribusiness includes all those business and management activities performed by firms that provide inputs to the farm sector, farm produce products, and/or process, transport, finance, handle or market farm products". According to Davis and Goldberg [6], "The sum total of all operations involved in the manufacture and distribution of farm supplies; production operations on the farm; and the storage, processing, and distribution of the resulting farm commodities and items". According to Beierlein and Woolverton [2] "Agribusiness includes not only those that farm the land but also the people and firms that provide inputs (e.g, milk, grain, meat), manufacture the food products (e.g., ice cream, bread, breakfast cereals), and transport and sell the food products to consumers (e.g., restaurants, supermarkets).

Based on these definitions, agribusiness management is not only studying agribusiness and management but also requires a theory of decision making. Rapid technological advances, information explosion, and the widening gap between the developed and underdeveloped countries of the world all contribute to today's complex environment [5]. The complexity of the agricultural industry is well documented. Other factors that contribute to complexity in agriculture include demographic issues (poverty, high population growth, and income growth rates), dietary and consumer preference changes, government action, agricultural research, land use, and climatic changes [21].

The characteristics of this environment, coupled with managers' less-than-perfect rationality, lead managers to formulate mental models of their environment and to rely, to some degree, on these during decision-making [15]. One of the issues that must be determined by an agribusiness manager is establish the networks among agribusiness companies. System dynamics modeling is one of a number of tools that can help managers learn and revise their mental maps of their business environment, and thereby improve decision making and performance [8].

This research develop the model of decision making in the agribusiness management system through serious game. This research is designed to simulate a model of networks among agribusiness managements. By studying networks among agribusiness managements are expected to be used as a reference for decision making. This research offers a methodological contribution, reveals how the modeling approach is applied to other systems such as the problems of social networks [17], bank networks [3] and relational data [24] can be used to study the networks in agribusiness management.

The rest of this paper is organized as follows. The theoretical consideration that supports the implementation method is described in section 2. The proposed model for agribusiness management modelling and data modelling are discussed in section 3. Section 4 gives the experiment results. Finally conclusions are given insection 5

\section{THEORETICAL CONSIDERATION}

\section{Agribusiness management}

Responsibility and management functions in agribusiness management are not differ from another management. However, the field of agribusiness has high complexity on their activities. The role of management in agribusiness so widely, from preparing (order), input before production began, seek employee and dismiss them, and to make the sale.

According to the management principles in agribusiness management functions can be grouped into Marketing Management, Financial Management, Operations Management and Human Resources Management.

Marketing management is the process of planning and executing the conception, pricing, promotion, and distribution of ideas, goods, and services to create exchanges that satisfy individual and organizational goals [16].

Financial Management is mainly concerned with the effective funds management in the business. In simple words, Financial Management as practiced by business firms can be called as Corporation Finance or Business Finance. Financial management is one of the important parts of overall management, which is directly related with various functional departments like personnel, marketing and production. Financial management covers wide area with multidimensional approaches [4].

Operations Management is the activity of managing the resources which produce and deliver goods and services [26]. Operations can be seen as one of many functions (e.g. marketing, finance, personnel) within the organisation. The operations function can be described as that part of the organisation devoted to the production or delivery of goods and services. This means all organisations undertake operations activities because every organisation produces goods and/or services.

Human resource management (HRM) is the governance of an organization's employees. HRM is sometimes referred to simply as human resources (HR). A company's human resources department is responsible for creating, implementing and/or overseeing policies governing employee behaviour and the behaviour of the company toward its employees. Human resources are the people who work for the organization; human resource management is really employee management with an emphasis on those employees as assets of the business. In this context, employees are sometimes referred to as human capital. As with other business assets, the goal is to make effective use of employees, reducing risk and maximizing return on investment $(\mathrm{ROI})$. Areas of HRM oversight include - among many others -- employee recruitment and retention, exit interviews, motivation, assignment selection, labor law compliance, performance reviews, training, professional development, mediation, and change management [18]. 


\section{Decision Making Process}

Herbert A. Simon developed a model of decision making. The model consisted of three steps, intelligence, design, and choice [25]. The intelligence phase consists of finding, identifying, and formulating the problem or situation that calls for a decision. This has been called deciding what to decide. The intelligence stage may involve, for example, comparing the current status of a project or process with its plan. The end result of the intelligence phase is a decision statement. The design phase is where we develop alternatives. This phase may involve a great deal of research into the available options. During the design phase we should also state our objectives for the decision we are to make. In the choice phase, we evaluate the alternatives that we developed in the design phase and choose one of them. The end product of this phase is a decision that we can carry out.

Herbert A. Simon introduced another oft-quoted aspect of decision: the distinction between programmed decision and non-programmed decision [24]. He stated: "Decisions are programmed to the extent that they are repetitive and routine, to the extent that a definite procedure has been worked out for handling them so that they don't have to be treated from scratch each time they occur" [24]. Decisions on the other hand are non-programmed "to the extent that they are novel, unstructured and unusually consequential" [24]. The fundamental unity of Simon's thinking is evident here, for organizations, like computers, are systems designed for "complex information processing" [24]. The processing of information for decision is the key to the whole of Simon's work. Programmed decisions obey computer programs or other programs that are computerizable, while nonprogrammed decisions come under the heading of "problem solving" [24].

Henry Mintzberg has identified ten Sub roles common to the work of all managers. The ten roles are divided into three groups: interpersonal roles, informational roles, and decisional roles [19].

Informational roles involves the role of assimilating and disseminating information as and when required. Following are the main sub-roles, which managers often perform: (a) Monitor-collecting information from organizations, both from inside and outside of the organization, (b) Disseminator-communicating information to organizational members, (c) Spokespersonrepresenting the organization to outsiders [19].

Decisional roles involves decision making. This role can be subdivided in to the following: (a) Entrepreneur-initiating new ideas to improve organizational performance, (b)Disturbance handlers-taking corrective action to cope with adverse situation, (c) Resource allocators-allocating human, physical, and monetary resources, (d) Negotiator - negotiating with trade unions, or any other stakeholders [19].

Interpersonal roles involves activities with people working in the organization. This is supportive role for informational and decisional roles. Interpersonal roles can be categorized under three subheadings: (a) Figurehead-Ceremonial and symbolic role, (b) Leadership-leading organization in terms of recruiting, motivating etc, (c) Liaison-liasoning with external bodies and public relations activities [19].

\section{Serious Game}

A serious game is a game designed for a primary purpose other than pure entertainment. The 'serious' adjective is generally pretended to refer to products used by industries like defense, education, scientific exploration, health care, emergency management, city planning, engineering, religion, and politics [23]. In this research serious game is used to simulate the agribusiness management for decision making.

Serious games are designed for the purpose of solving a problem. Although serious games can be entertaining, their main purpose is to train, investigate, or advertise. Sometimes a game will deliberately sacrifice fun and entertainment in order to make a serious point. Whereas video game genres are classified by game play, serious games are not a game genre but a category of games with different purposes. This category includes educational games and advergames, political games, or evangelical games [1].

There are four levels of serious games: observe game, experiment game, collaborate game, and manage game [12]. First, an observe game implies that the interaction with the virtual model is limited to watching the behavior of a virtual system with a predetermined set of parameters. Second, an experiment game implies an observe game plus the interaction that can change parameters to produce a predicted result and then observe the simulated results. Comparisons can be made between predicted and simulated to understand the dynamic of the model. Further, comparisons can be made between the simulated results and actual observations in the real world to improve the validity of the model. Third, collaborate game implies an experiment game plus multiple persons can simultaneously interact with the model. The social interaction adds new dimensions in coordination and collaboration. The assumption is that the resulting quality will be better if many individuals can collaborate together within an effective environment. Fourth, manage game implies a collaborate game plus the interaction can change parameters, not only in the virtual system, but also to control the real system. Comparisons of the simulated versus actual behavior can be used to manage the real system toward desirable goals. The essential aspects of any complex system can be modeled as a serious game in a virtual world. One can observe the current state of the system, experiment with different strategies, collaborate on team efforts, and even manage processes within the system. 


\section{METHODE}

\section{Agribusiness Management Modelling}

The basic philosophy surrounding the phenomenon of supply chain on the relationship between a firm and its suppliers and customers. Edwards describes this as follows: In a supply chain, a company links to its suppliers upstream and to its distributors downstream in order to serve its customers [10]. Usually, materials flow forward while information and money flow backward in the chain as shown in Fig. 1. The goal of supply chain management is to provide maximum customer service at the lowest possible costs.

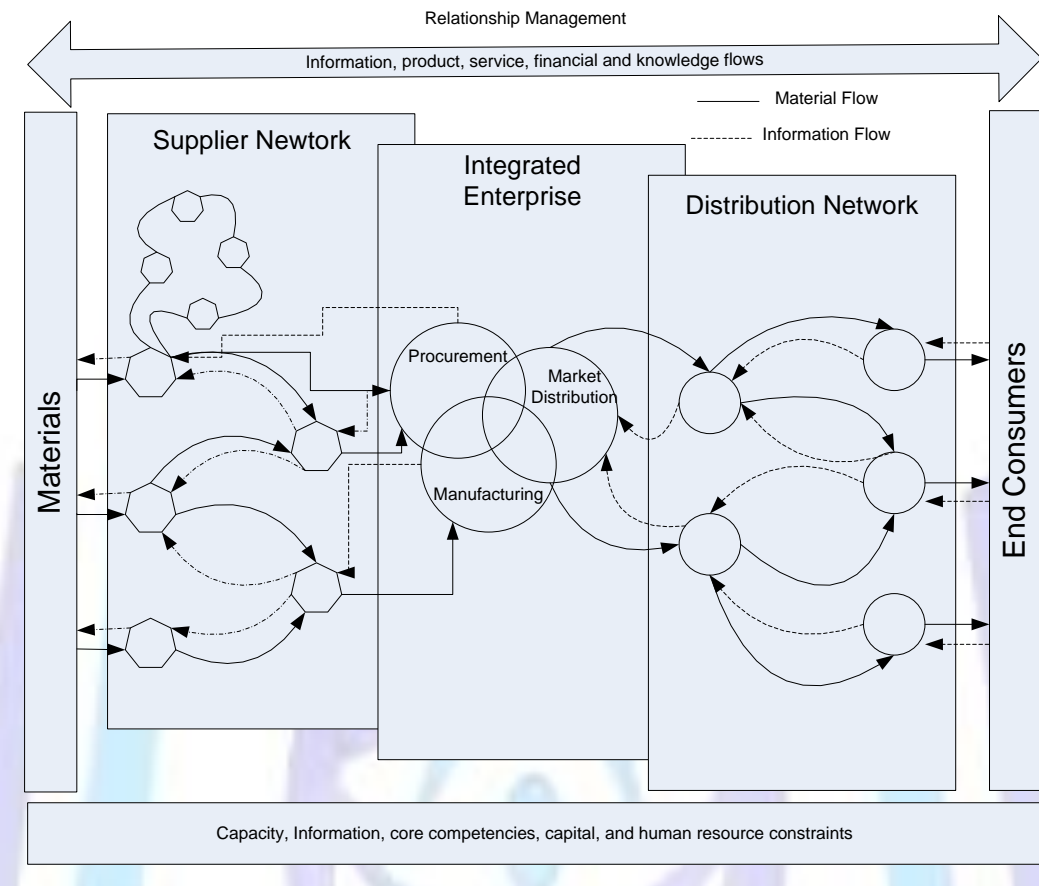

Figure 1.

Network model on company, suppliers and buyers [11]

The organization can create 'value' for itself and its customers by participating in value chain activities [22]. The value derived from the relationship evolves into a key resource [20], and value is therefore amassed as the cumulative worth of all the exchanges that occur between the participating firms [13].

The description of the nature of relationships in agribusiness enterprises above highlighted the traditional concept of firms. Traditionally firms were viewed as a discrete and independent entity. In determining the strategy that chosen, firms sought to reinforce independence [7]. This concept has been changed to be network based strategies. The contemporary concept is that firms are embedded in network or web of interdependent relationships and as such firms need a strategic approach to the management of such relationships. The following diagram illustrates the nature of relationships that modern day firms engage into in their day to day competitive environment [7].

In order to meet stakeholder expectations and to achieve their strategic intent, firms must pursue a dynamic mix of both competitive and cooperative strategies. As depicted in the diagram above, De Wit \& Meyer argue that firms need network strategies to manage relationships with three different types of players around their supply chain environments as follows: (a) Upstream with suppliers and downstream with customers, (b) Horizontally with competitors and complementors, (c) with other key players in the economic, political/regulatory, technological and socio-cultural environments [7] as shown in Fig. 2. 


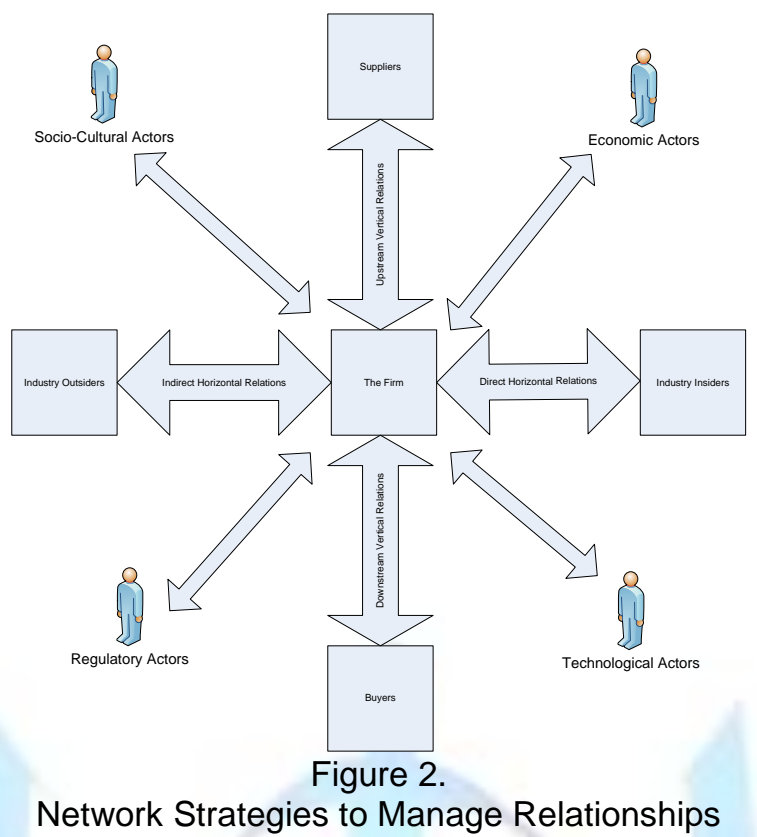

\section{Data Modelling}

This relationship management strategy aims to increase the investment. Investment (I) depends on income at the time when the investment decisions are taken and on capital stock at the time when investment will be finished. The latter is a consequence of the fact that in time $t$ - $T$ there are some investments which will be finished between $t-T$ and $T$. In this research we assume that capital stock produced in this period is taken into consideration when new investments are planned.

The saving function (S) depends only on $Y$ (gross product) and is linear such that $S_{Y}=Y \in(0,1)$. Additionally. we assume that the investment function $\mathrm{I}(\mathrm{Y}, \mathrm{K})$ separates in respect to its two arguments ( $\mathrm{Y}$ is gross product and $\mathrm{K}$ is capital stock) and $\mathrm{I}_{\mathrm{y}}>0, \mathrm{I}(\mathrm{K})$ is linear such that $\mathrm{I}_{\mathrm{K}}=\beta<0$ then

$$
\mathrm{I}(\mathrm{Y}, \mathrm{K})=\mathrm{I}(\mathrm{Y})+\beta \mathrm{K}
$$

After substituting the above assumption into the Kaldor-Kalecki dynamical system, we have

$$
\begin{aligned}
& \frac{d Y}{d t}=\alpha I(Y(t))+\alpha \beta K(t)-\alpha y Y(t) \\
& \frac{d K}{d t}=I(Y(t-T))+(\beta-\delta) K(t)
\end{aligned}
$$

The critical points of delay system coincide with the corresponding points for finishing delay because stationary states do not depend on translation of time. The critical points of $\mathrm{K}(\mathrm{CK})$ is shown in Eq.4.

$$
\mathrm{CK}=\frac{\mathrm{I}(\mathrm{CY})}{\delta-\beta}
$$

and the critical points of $Y(C Y)$ is shown in Eq.5.

$$
\mathrm{CY} \rightarrow \mathrm{I}(\mathrm{CY}) \frac{\delta}{\beta-\delta}+\mathrm{YCY}=0
$$

Data modeling entangles attribute analysis for finding relationship between agribusiness. Activity network prediction, which will be formed, entangles the relation of variable y (two nodes will be formed new activity network depend on value of variable $b$ and variable $\mathrm{x}$ ) as shown in Eq.6. There are some technique for finishing these problems, for example linear regression, logistics regression, network Bayesian and clustering. Hosmer and Lemeshow recommend logistics regression as appropriate method for binary data [14]. The logistics regression as shown in Eq. 6.

$$
y=b_{0}+b_{1} x_{1}+b_{2} x_{2}+\ldots+b_{n} x_{n}
$$

$\mathrm{x} 1, \mathrm{x} 2 \ldots, \mathrm{xn}$ in this paper are estimator variable, in this case is agribusiness which will be formed activity network. Coefficient b0, b1, .., bn are carrying capacity of area, in this case are relational vertically, horizontally and other relationships. in this research, we are using sinthetic data. Hosmer and Lemeshow was map Xn to Xn+1 as shown in Eq.7 [14]. 


$$
X_{n+1}=\lambda X_{n}\left(1-X_{n}\right)
$$

Behavior of $X n$, if it moves with small distance from fixed point will be yield $X n+1$ that condition can know from derivative of fixed point that is $\frac{d X_{n+1}}{d X_{n}}$ by equation as shown in Eq. 8.

$$
\frac{d X_{n+1}}{d X_{n}}=\lambda\left(1-2 X_{n}\right)
$$

The fixed point at $X_{n}=0$ is $\frac{d X_{n+1}}{d X_{n}}=\lambda$. Fixed point $(\lambda)$ in this research is The critical points (CK). The fixed point at $X_{n}=\frac{\lambda-1}{\lambda}$ is $\frac{d X_{n+1}}{d X_{n}}=2-\lambda$. Slope in the second fixed points,

$X_{n}=\frac{\lambda-1}{\lambda}, \frac{d X_{n+1}}{d X_{n}}=2-\lambda$

show that:

$\lambda$ in the $0<\lambda \leq 1$ range, fixed point is $\mathrm{Xn}=0$ (attractor), $\lambda$ in the $1<\lambda \leq 2$ range, fixed point is $X_{n}=\frac{\lambda-1}{\lambda}, \lambda$ in the $2<\lambda$ $\leq 3$ range, slope of the fixed point is negative and $X n$ oscillate around fixed point and convergent, $\lambda$ in the $3<\lambda \leq 2$ range, fixed point starts oscillation.

\section{EXPERIMENTAL RESULTS}

Based on agribusiness management modeling and data modeling, there are inter-corporate network conditions possible forms:
1) Mutual independence,
2) Unbalanced independence,
3) Mutual dependence, and
4) Unbalanced dependence.

The four relational, which is formed, influenced by environmental capacity in this case is the analysis of relational conditions vertically, horizontally and other relationships as shown in Fig. 3.
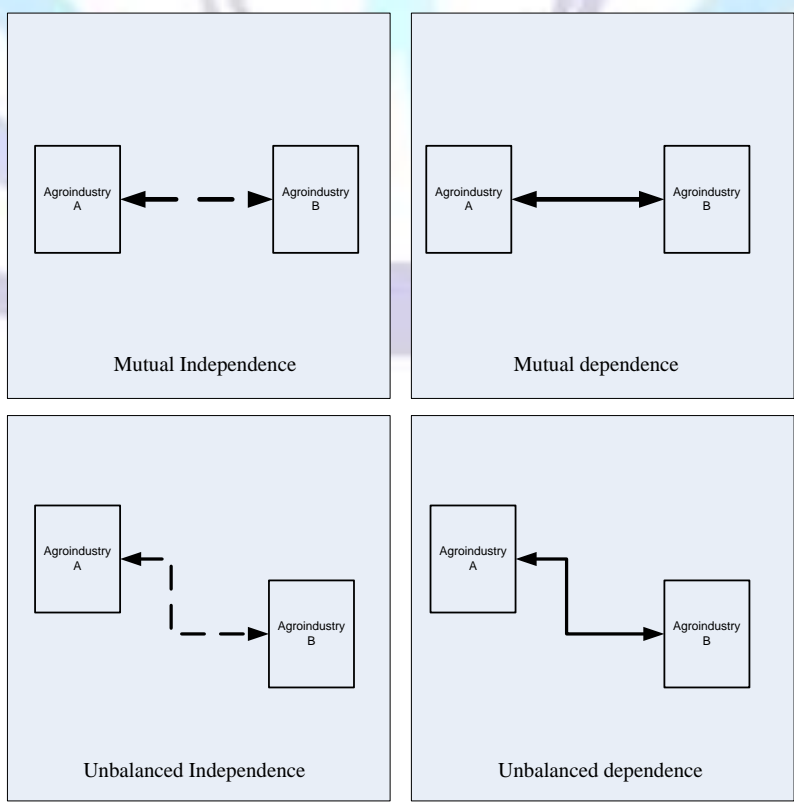

Figure 3.

The Probability of Inter-corporate Network 
Fig. 3 shows that the mutual dependence condition requires a strategic approach by network management in order to maintain the balancing networks. The condition of mutual independence need to maintain a level of independence than to maintain the integrity of the network. The unbalanced dependence condition requires a strategic approach to manage the network that can create a balance networks. The unbalanced independence condition requires to strengthen the independence of the firm.

The fourth condition of networks among agribusiness managemen (mutual independence, unbalanced independence, mutual dependence, and unbalanced dependence) can be detected by serious games of the agribusiness management using agribusiness management modelling and data modeling as shown in Fig. 4.

The results of the serious game show that mutual dependence conditions represented by $\mathrm{x}$ values start with degradation drastically from the initial value come towards stable value near 0 . This condition gives advice to agribusiness management in order to emphasize the strategy of balancing networks..

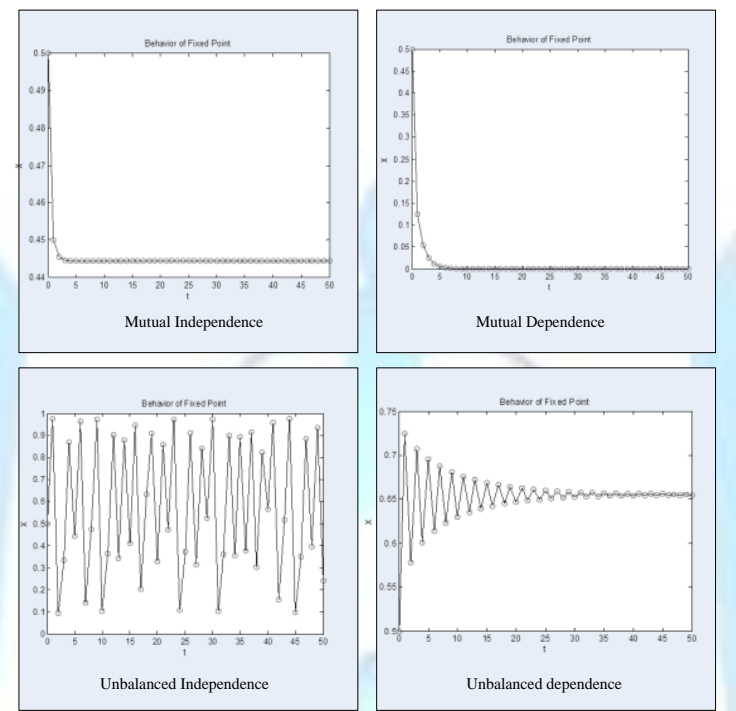

Figure 4.

The Fourth Conditions of Inter-corporate Network

The mutual independent condition represented by $x$ values start with degradation drastically from the initial value stability towards stable value but value still not yet come near 0 . This condition suggest to agribusiness management that are simulated to maintain a level of independence than preserving the integrity of networks

The unbalanced dependence condition represented by the $\mathrm{x}$ values oscillates around a fixed point and converge. This condition suggest to agribusiness management that are simulated to create a balance networks.

The unbalanced independence condition represented by the $\mathrm{x}$ values start to oscillate. This condition suggest to agribusiness management that are simulated to strengthen its independence.

The fourth possible condition among agribusiness networks (mutual independence, unbalanced independence, mutual dependence, and unbalanced dependence) have an influence on the number of received global network, number of rejected global networks, distribution of capital stock in agribusiness and distribution of gross product as shown in Fig. 5 .
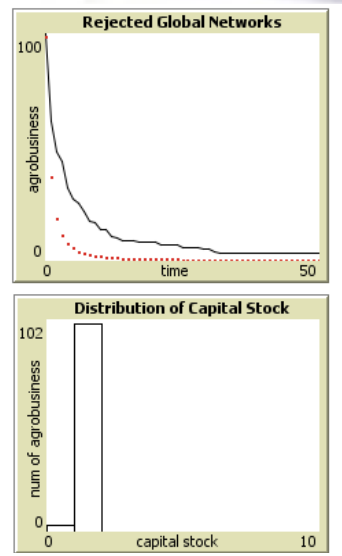
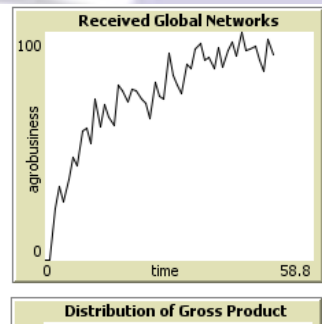

103

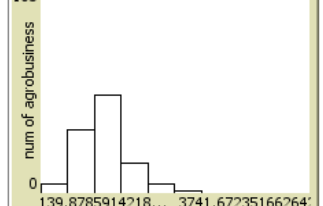

Figure 5 .

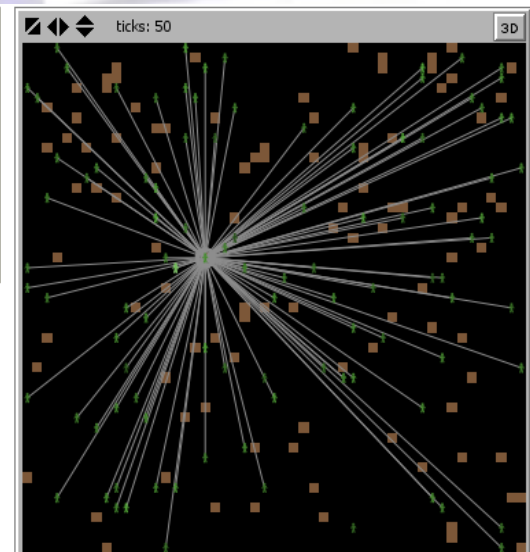

Simulation of The Serious Game 


\section{CONCLUSIONS}

The results of the research show that there are four condition of networks among agribusiness managemen: (1) mutual independence, (2) unbalanced independence, (3) mutual dependence, and (4) unbalanced dependence.

The mutual dependence conditions represented by $x$ values start with degradation drastically from the initial value come towards stable value near 0 . This condition gives advice to agribusiness management in order to emphasize the strategy of balancing networks.

The mutual independent condition represented by $x$ values start with degradation drastically from the initial value stability towards stable value but value still not yet come near 0 . This condition suggest to agribusiness management that are simulated to maintain a level of independence than preserving the integrity of networks

The unbalanced dependence condition represented by the $\mathrm{x}$ values oscillates around a fixed point and converge. This condition suggest to agribusiness management that are simulated to create a balance networks.

The unbalanced independence condition represented by the $\mathrm{x}$ values start to oscillate. This condition suggest to agribusiness management that are simulated to strengthen its independence.

\section{ACKNOWLEDGMENTS}

Our thanks to the Director General of Higher Education for funding this research through the "Hibah Penelitian Unggulan Perguruan Tinggi" by contract number 362/UN25.3.1/LT.6/2013

\section{REFERENCES}

[1] Anne Derryberry, 2007, Serious games: online games for learning, Retrieved August 20, 2013, www.imserious.net

[2] Beierlein, James G. \& Woolverton, Michael. W., 1991, Agribusiness Marketing, Englewood Cliffs, New Jersey: Prentice Hall.

[3] Bukhori S., M. Hariadi, I Ketut Eddy P, Mauridhi Heri P, 2009, "Exploring Agent-Based Methods for Activity Network Prediction in Real Time Gross Settlement (RTGS) Based on Clearing House", International Journal of Computer Science and Network Security.

[4] C.Paramasivan and T. Subramanian,Financial management, New Age International Publisher, Retrieved August 20 2013, http://vcmdrp.tums.ac.ir/files/financial/istgahe_mali/moton_english/financial_managementpdf

[5] Daellenbach, H. G., 1994, Systems and decision making: a management science approach, New York: John Wiley \& Sons, Inc.

[6] Davis, J. H., and R. A. Goldberg, 1956, A concept of agribusiness, Research Division,Harvard Business School, Boston, MA.

[7] De Wit, B. \& Meyer, R., 2004, Strategy: Process, Content, Context, Third Edition. Thomson

[8] Donna K. Fisher, Jonathan Norvell, Steven Sonka and Mark J. Nelson, 2001, Understanding technology adoption through system dynamics modeling: implications for agribusiness management, International Food and Agribusiness Management Review 3, 281-296.

[9] Downey, D. W., and S. P. Erickson, 1987, Agribusiness Management, 2nd edition. New York: McGraw-Hill, Inc.

[10] Edwards, P.J., and Bowen, P.A., 1998, Risk and Risk Management in Construction: A Review and Future Direction for Research, Engineering Construction and Architectural Management, Vol. 5, No. 4, pp. 339-349.

[11] Georgevitch, S, 2007.,Business model \& supply chain overview. Presentation on March 15, 2007 at the Air Force Logistics Transformation Forum.

[12] Hackathorn, R., 2007, Serious Games in Virtual Worlds: The Future of Enterprise Business Intelligence, Retrieved August 20, 2013, http://www.b-eye- network.co.uk /view-articles/4163.

[13] Hogan, 1. E., 2001, Expected relationship value, a construct, a methodology for measurement, and a modelling technique, Industrial Marketing Management, 30339-351.

[14] Hosmer, DW \& Lemeshow, S, 1989, Applied logistic regression, John Wiley \& Sons, New York.

[15] Huff, A. H., 1990, Mapping strategic thought, New York, John Wiley \& Sons, Inc.

[16] Kohls \& Url, J.N, 1980, Marketing of Agricultural Product, Fifth End. Collar.Macmillan Publishing Company, New York.

[17] Liben-Nowell, D \& Kleinberg, 2003, The link prediction problem for social networks, Proceedings of the twelfth international conference on information and knowledge management.

[18] Luis R. Gomez-Mejia, David B. Balkin, and Robert L. Cardy, 1995, Managing Human Resources (Upper Saddle River, NJ: Prentice-Hall. 
[19] Mintzberg, H., 1973, The nature of managerial work, New York: Harper \& Row.

[20] Morgan, R. M., \& Hunt, S. D., 1994, The commitment-trust theory of relationship marketing. Journal of Marketing.

[21] Pinstrup-Andersen, P., \& Pandya-Lorch, R. , 1998, Major uncertainties and risks affecting long-term food supply and demand. In Organization for Economic Co-Operation and Development (OECD), The future of food: long-term prospects for the agro-food sector, Paris

[22] Porter, M. E., 1985, Competitive advantage, creating and sustaining superior performance, The Free Press, New York.

[23] Richard Naish, 2005, Serious games get really serious, Retrieved August 20, 2013, www.elearningage.co.uk.

[24] Simon, H.A., 1977, The New Science of Management Decision, 3rd revised edition; first edition 1960) Prentice-Hall, Englewood Cliffs, NJ.

[25] Simon, H. A., 1978, Rational decision-making in business organizations. Retrieved August 20, 2013, from Nobel Prize Website:http://www.nobelprize.org/nobel_prizes/ economics /laureates/1978/simon-lecture.pdf

[26] Slack, N; Chambers, S; Johnston, R 2010, Operations Management , 6th edn, Pearson Education Limited, Harlow.

\section{Author' biography with Photo}

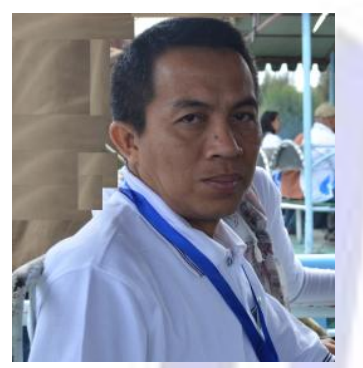

Saiful Bukhori received the bachelor degree in Electrical Engineering from Brawijaya University, Malang, Indonesia in 1993. He received both Magister Computer and Doctoral degrees in Sepuluh Nopember Institute of Technology (ITS), Surabaya, Indonesia, in 2003 and 2011, Currently, he is the staff of Information System Department in Jember University. His current interest's research areas are Informatics, Artificial Intelligence and Game Technology.

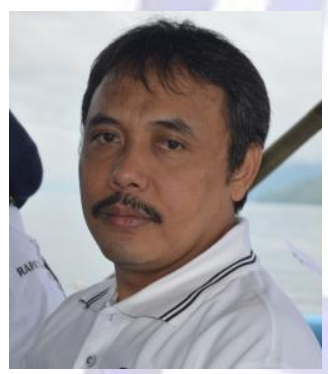

Anang Andrianto received the bachelor degree in Electrical Engineering from Brawijaya University, Malang, Indonesia in 1995. He received MT degrees in Sepuluh Nopember Institute of Technology (ITS), Surabaya, Indonesia, in 2000, Currently, he is the staff of Information System Department in Jember University. His current interest's research areas are Telecomunication and Computer Engineering

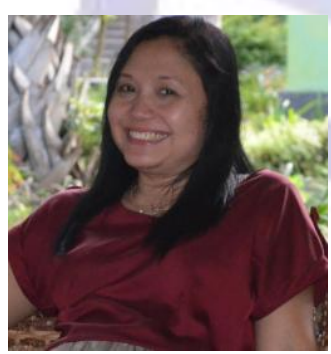

Wiji Utami received the bachelor degree in Economis from Jember University, Jember, Indonesia in 1997. He received MSi degrees in Airlangga University, Surabaya, Indonesia, in 2001, Currently, he is the staff of Economics Faculty in Jember University. His current interest's research areas is management resources. 